\title{
ASSESSMENT OF OPTIMUM TIP SPEED RATIO OF WIND TURBINES
}

\author{
N.S. Çetin ${ }^{1}$, M.A. Yurdusev ${ }^{2}$, R. Ata ${ }^{3}$ and A. Özdamar ${ }^{1}$ \\ ${ }^{1}$ Ege University, Mechanical Engineering Department, Bornova, İzmir-Turkey. \\ ${ }^{2}$ Celal Bayar University, Civil Engineering Department, Manisa-Turkey. \\ ${ }^{3}$ Celal Bayar University, Electrical Engineering Department, Manisa-Turkey.
}

\begin{abstract}
The first thing to do in wind turbine blade design is to select tip speed ratio. Generally speaking, the speed ratio depends on the profile type used and the number of blades. Various speed ratios could be chosen for different types of profiles with different number of blades. Therefore, an optimization procedure should be applied to find the best ratio since this directly affects the energy generated from the turbine and in turn the investment made. This study presents a procedure to assess the optimum speed ratios for various profile types used in practice with various numbers of blades.
\end{abstract}

Keywords: Wind turbine, design tip speed ratio, turbine blade, power factor.

\section{INTRODUCTION}

Wind is an atmospheric phenomenon that occurs as a result of the movement of air masses from where there is relatively higher pressure to low-pressure areas. The high-pressure areas in the atmosphere are also relatively colder then low-pressure places. During this movement, the heat energy transforms into kinetic energy.

Winds can be classified according to their blowing patterns: The first group blow in certain times of the year and can be called discrete winds. Monsoons and tornados can be given of example for this group. The second group consists of winds blowing all year continuously. Alizes move from the high-pressure band in southern part of the world towards the equator, which is a low-pressure zone. On the other hand, counter-alizes blow otherwise. Besides, there are winds blowing continuously from sea to land and vice versa. These winds develop due to the temperature difference between the air masses over sea and land. There is also another wind called fohn, which takes place in mountainous areas. Meeting with a mountain, a mobile air masse gets colder $0,5{ }^{\circ} \mathrm{C}$ for 100 meters elevation when it climbs the mountain and vice versa.

A wind turbine transforms the energy of the wind blowing trough its blades into mechanical energy. It comprises manly three parts; turbine blades, turbine body and turbine mil that is connected to the gear box which is subsequently connected to a generator by a rotary shaft. A tower carries all these equipment, which form the wind power plant.

Wind turbines can be classified as to whether they use resistance or uplift forces, whether the turbine axis is horizontal or vertical and the number rotation at the same wind velocity. In resistance turbines, there is a flat surface which rotates due to the wind pressure applied, whereas wind comes towards the blade by an angle in turbines utilizing uplift forces. The uplift force that takes place normally to the direction of wind velocity produces the rotation in this type of turbines. There is high pressure before the surface whereas low pressure after it.

Another classification for the wind turbines is made based on their nominal power values. Those having power values up to $5 \mathrm{~kW}$ are called small-power turbines whereas those with more power values are large power ones. 
Assessment of tip speed ratio is key to wind turbine blade design. This is recommended to be between 6 and 8. For example, for a grid connected wind turbine with 3 blades, the optimum ratio is suggested as 7 [1-2]. However, the speed ratio is dependent upon the profile type used and the number of blades the turbine has and therefore, should not necessarily between 6 and 8, since it can take different values as to the type of profile and the blade number. Besides, as it will be explained later the energy produced is directly related to the speed ratio selected and its choice deserves a careful selection process.

In this study, firstly the parameters affecting the power factor that can be defined as turbine yield are analyzed. Then the optimum speed ratios are determined for different types of blade profiles with several number of blades The profile types selected are NACA 4415, LS-1, Clark Y, Gottingen-398, C-80, M-6, Raf-15 and NACA 2212 [1-2]. The numbers of blades considered are 1,2,3 and 4.

\section{POWER FACTOR}

The circumstantial speed in meter per second $(\mathrm{m} / \mathrm{sec})$ of a blade element of a wind turbine located at a distance from the cent can be expressed as;

$\mathrm{V}_{\mathrm{c}}=\omega \mathrm{r}$

where $w$ is angular velocity. $\mathrm{n}$ being the number of rotation of turbine mile in a minute, this becomes

$\omega=\frac{\pi \mathrm{n}}{30}$

Substituting Eqn. 2 in Eqn. 1 yields;

$\mathrm{V}_{\mathrm{c}}=\frac{\pi}{30} \mathrm{nr} \quad(\mathrm{m} / \mathrm{s})$

The speed ratio or the end velocity ratio is then can be defined as

$\lambda_{\mathrm{A}}=\frac{\mathrm{V}_{\mathrm{c}}}{\mathrm{V}_{\mathrm{r}}}$

where $V_{r}$ is the wind speed. From the Eqn. (3) and (4) $\lambda_{A}$ can be written as,

$$
\lambda_{\mathrm{A}}=\frac{\pi \mathrm{r}}{30} \frac{\mathrm{n}}{\mathrm{V}_{\mathrm{r}}}
$$

The power factor, $\mathrm{C}_{\mathrm{p}}$, can be expressed as the ratio between the power in turbine mile, $\mathrm{P}_{\mathrm{p}}$, and that due to kinetic energy of wind before the turbine surface, $\mathrm{P}_{\mathrm{r}}$, which is;

$$
C_{P}=\frac{P_{P}}{P_{r}}
$$

The power generated in Watt by kinetic energy of the air flow passing through a circle with a radius of $\mathrm{R}$ before the turbine surface can be stated as;

$$
P_{r}=\frac{1}{2} \rho \pi R^{2} V_{r}^{3} \quad(\text { Watt } \Rightarrow N m / s)
$$

The maximum power factor is 0,5926 which is called the Betz limit and the productivity obtained in practice can be $45 \%$ at the maximum [5]. The reasons why the real productivity is less than the theoretical one are the losses that are not considered in theory. These losses are 
- profile losses

- end losses

- whirlpool losses

- blade number losses

The profile losses: In equation (6), the resistance force was neglected. This can be considered using,

$\eta_{\text {profile }}=1-\left(\lambda_{\mathrm{A}} / \varepsilon\right)$

where $\varepsilon$ is the number of slip(slide) and can be expressed as the ratio of the uplift force coefficient of the chosen profile $C_{L}$ to resistance force coefficient $C_{D}$ which is

$\varepsilon=\frac{\mathrm{C}_{\mathrm{L}}}{\mathrm{C}_{\mathrm{D}}}$

The end losses: In the end of a blade, there takes place on airflow from the lower side of the profile to the upper side. Coupling with the airflow coming to the blade, this airflow generates a gradually widening. In the calculations, this can be considered as

The whirlpool losses: According to the Betz theory the wind does not change before and after the turbine plate. However the air mass encountering the blade changes its direction. The whirlpool losses can be calculated by $C_{\text {pschmitz }}-\lambda_{A}$ diagram given by Schmitz [2] if the same profile is used throughout the blade. The $C_{p s c h m i t z}-\lambda_{A}$ curve is given in Figure 1 and the numerical values associated with this diagram in Table 1.

Blade number losses: In a turbine with more than four blade, the air movement through blades gets complicated and its theoretical analysis can not easily be made. Therefore, the theory of Glauert-Shmitz previously mentioned applies to the turbines with four our less wind turbine blade.

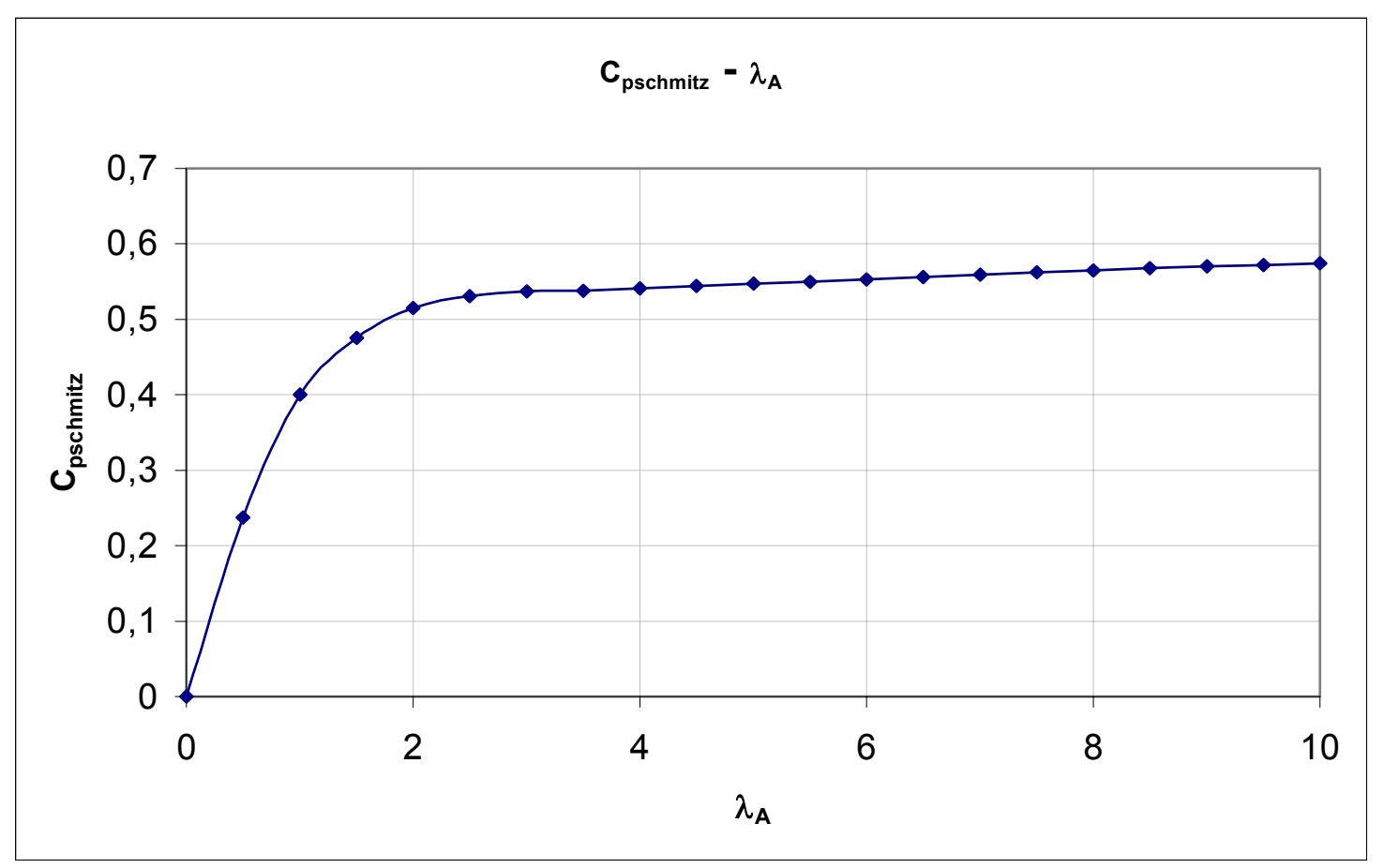

Figure $1: \mathrm{C}_{\mathrm{pschmitz}}-\lambda_{\mathrm{A}}$ curve 
Having considered all the losses mentioned, the power factor given in Eqn. 6 becomes; $\mathrm{C}_{\mathrm{p}}=\mathrm{C}_{\mathrm{pschmitz}}\left(\lambda_{\mathrm{A}}\right) \cdot \eta_{\text {profil }}\left(\lambda_{\mathrm{A}}, \varepsilon\right) \cdot \eta_{\text {end }}\left(\lambda_{\mathrm{A}}, \mathrm{z}\right)$

Table 1: $C_{\text {pschmitz }}-\lambda_{A}$ values for whirpool lossess

\begin{tabular}{|c|c|}
\hline$\lambda_{\mathrm{A}}$ & $\mathrm{C}_{\text {Pschmitz }}$ \\
\hline 0 & 0 \\
\hline 0,5 & 0,238 \\
\hline 1 & 0,400 \\
\hline 1,5 & 0,475 \\
\hline 2 & 0,515 \\
\hline 2,5 & 0,531 \\
\hline 3 & 0,537 \\
\hline 3,5 & 0,538 \\
\hline 4 & 0,541 \\
\hline 4,5 & 0,544 \\
\hline 5 & 0,547 \\
\hline 5,5 & 0,550 \\
\hline 6 & 0,553 \\
\hline 6,5 & 0,556 \\
\hline 7 & 0,559 \\
\hline 7,5 & 0,562 \\
\hline 8 & 0,565 \\
\hline 8,5 & 0,568 \\
\hline 9 & 0,570 \\
\hline 9,5 & 0,572 \\
\hline 10 & 0,574 \\
\hline
\end{tabular}

\section{PARAMETER INVESTIGATION}

In this study, to the optimum design speed ratio of a wind turbine is investigated for the profile types mostly used in practice. The types considered include NACA 4415, LS-1, Clark Y, Gottingen-398, C-80, M-6, RAF-15 and NACA 2212. The investigation was made for the blade numbers 1, 2, 3 and 4 and angels of $0,5,10$ and 15 degrees. The values of all variables according to the parameters above are given in Tables 2,3 and 4 and Figures 2,3 and 4 for NACA 4415, LS-1 and Clark Y type turbines respectivelly. The optimum power factor as to the parameters considered is then be obtained. The curve for optimum power factor for each type is presented in the associated profile type.

\section{CONCLUSIONS}

The assessment of optimum design speed ratio of wind turbines is investigated for different type of profiles with different configurations. Having analyzed the findings of this study, it can easily be said that the optimum design speed ratio for every profile is different rather than being 7 as pointed out in related literature. This study has also 
showed that the suitable profile types for wind turbines are LS-1 (Table 3 and Figure 3), NACA 4415 (Table 2 and Figure 2) and Clark Y(Table 4 and Figure 4). The optimum speed ratios for these profiles are 10,8,5 and 3.5 respectively. A similar exercise for the other profile types used in wind turbines suggested different values for optimum speed ratio. These are 3.5 for M-6, NACA 2212, NACA 2412 , C-80 and Gottingen 398 profiles and 4 for RAF-15 profile.

Table 2: Calculated values for the profile type NACA 4415

\begin{tabular}{|c|c|c|c|c|c|c|c|c|c|c|}
\hline$\lambda_{\mathrm{A}}$ & $\mathrm{C}_{\mathrm{PS} \text { chmitz }}$ & $\begin{array}{c}\eta_{\text {end }} \\
(\mathrm{z}=1)\end{array}$ & $\begin{array}{c}\eta_{\text {end }} \\
(\mathrm{z}=2)\end{array}$ & $\begin{array}{c}\eta_{\text {end }} \\
(\mathrm{z}=3)\end{array}$ & $\begin{array}{c}\eta_{\text {end }} \\
(\mathrm{z}=4)\end{array}$ & $\begin{array}{c}\eta_{\text {profile }} \\
\left(\alpha=0^{0}\right)\end{array}$ & $\begin{array}{c}\eta_{\text {profile }} \\
\left(\alpha=5^{0}\right)\end{array}$ & $\begin{array}{c}\eta_{\text {profile }}\left(\alpha=10^{0}\right) \\
\mathrm{C}_{\mathrm{P} \text { opt3 }}\end{array}$ & $\mathrm{C}_{\mathrm{P} \text { opt4 }}$ \\
\hline 0,5 & 0,238 & $-2,680$ & $-0,840$ & $-0,228$ & 0,0800 & 0,9878 & 0,9922 & 0,9908 & $-0,053$ & 0,0189 \\
\hline 1 & 0,400 & $-0,840$ & 0,0800 & 0,3867 & 0,5400 & 0,9756 & 0,9845 & 0,9816 & 0,1523 & 0,2127 \\
\hline 1,5 & 0,475 & $-0,227$ & 0,3867 & 0,5911 & 0,6933 & 0,9633 & 0,9767 & 0,9724 & 0,2742 & 0,3217 \\
\hline 2 & 0,515 & 0,0800 & 0,5400 & 0,6933 & 0,7700 & 0,9511 & 0,9690 & 0,9632 & 0,3460 & 0,3843 \\
\hline 2,5 & 0,531 & 0,2640 & 0,6320 & 0,7547 & 0,8160 & 0,9389 & 0,9612 & 0,9540 & 0,3852 & 0,4165 \\
\hline 3 & 0,537 & 0,3867 & 0,6933 & 0,7956 & 0,8467 & 0,9267 & 0,9535 & 0,9448 & 0,4073 & 0,4335 \\
\hline 3,5 & 0,538 & 0,4743 & 0,7371 & 0,8248 & 0,8686 & 0,9144 & 0,9457 & 0,9355 & 0,4196 & 0,4419 \\
\hline 4 & 0,541 & 0,5400 & 0,7700 & 0,8467 & 0,8850 & 0,9022 & 0,9380 & 0,9263 & 0,4296 & 0,4491 \\
\hline 4,5 & 0,544 & 0,5911 & 0,7956 & 0,8637 & 0,8978 & 0,8900 & 0,9302 & 0,9171 & 0,4371 & 0,4543 \\
\hline 5 & 0,547 & 0,6320 & 0,8160 & 0,8773 & 0,9080 & 0,8778 & 0,9225 & 0,9079 & 0,4427 & 0,4582 \\
\hline 5,5 & 0,550 & 0,6655 & 0,8327 & 0,8885 & 0,9164 & 0,8655 & 0,9147 & 0,8987 & 0,4470 & 0,4610 \\
\hline 6 & 0,553 & 0,6933 & 0,8467 & 0,8978 & 0,9233 & 0,8533 & 0,9070 & 0,8895 & 0,4503 & 0,4631 \\
\hline 6,5 & 0,556 & 0,7169 & 0,8585 & 0,9056 & 0,9292 & 0,8411 & 0,8992 & 0,8803 & 0,4528 & 0,4646 \\
\hline 7 & 0,559 & 0,7371 & 0,8686 & 0,9124 & 0,9343 & 0,8289 & 0,8915 & 0,8711 & 0,4547 & 0,4656 \\
\hline 7,5 & 0,562 & 0,7547 & 0,8773 & 0,9182 & 0,9387 & 0,8166 & 0,8837 & 0,8619 & 0,4560 & 0,4662 \\
\hline 8 & 0,565 & 0,7700 & 0,8850 & 0,9233 & 0,9425 & 0,8044 & 0,8760 & 0,8527 & 0,4570 & 0,4665 \\
\hline 8,5 & 0,568 & 0,7835 & 0,8918 & 0,9278 & 0,9459 & 0,7922 & 0,8682 & 0,8435 & 0,4576 & 0,4665 \\
\hline 9 & 0,570 & 0,7956 & 0,8978 & 0,9319 & 0,9489 & 0,7800 & 0,8605 & 0,8343 & 0,4570 & 0,4654 \\
\hline 9,5 & 0,572 & 0,8063 & 0,9032 & 0,9354 & 0,9516 & 0,7677 & 0,8527 & 0,8250 & 0,4563 & 0,4641 \\
\hline 10 & 0,574 & 0,8160 & 0,9080 & 0,9387 & 0,9540 & 0,7555 & 0,8450 & 0,8158 & 0,4553 & 0,4627 \\
\hline
\end{tabular}




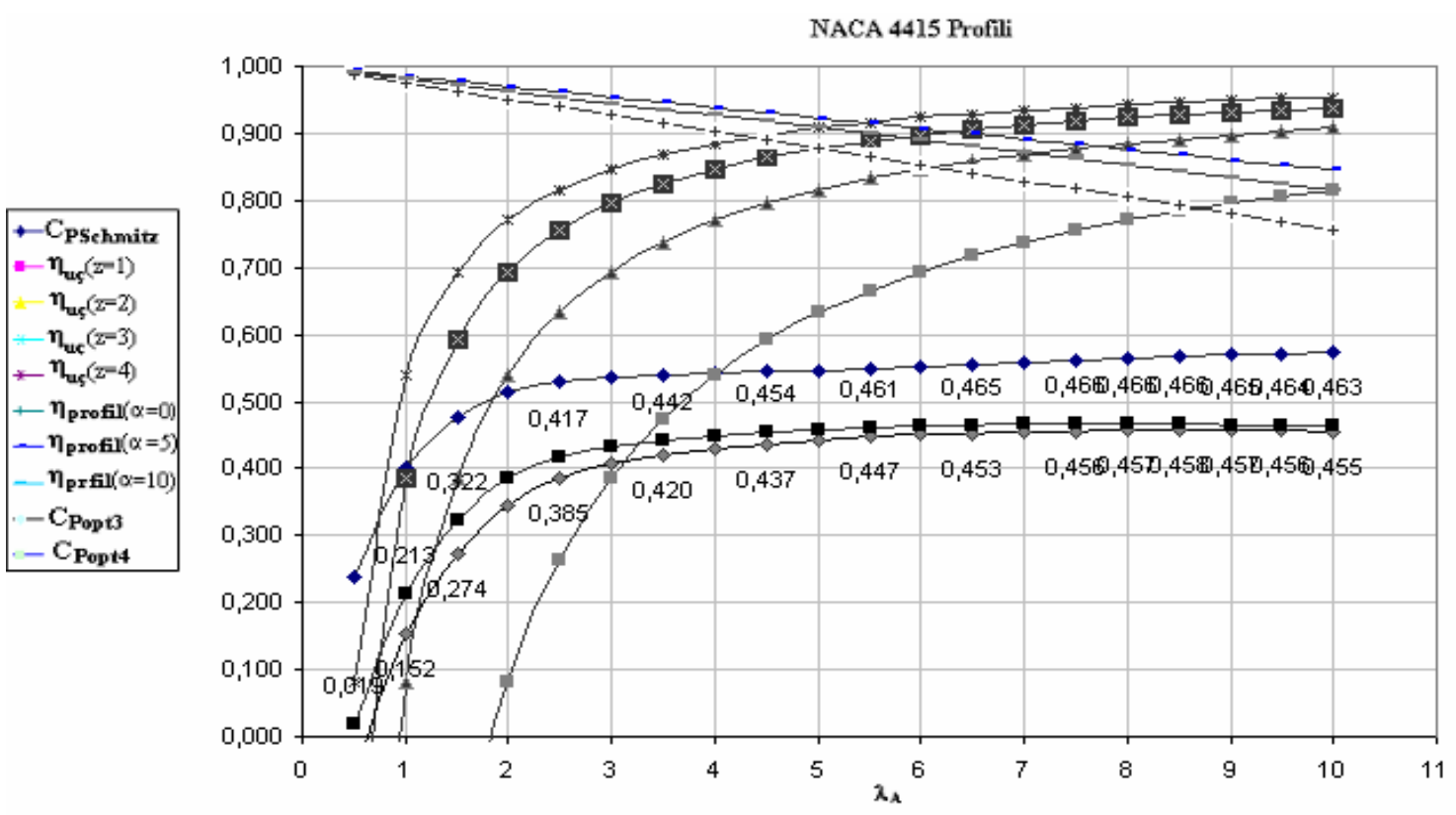

Figure 2: Plot of the values of the profile type NACA 4415

Table 3: Calculated values for the profile type LS-1

\begin{tabular}{|c|c|c|c|c|c|c|c|c|c|c|c|}
\hline A & $\begin{array}{l}\text { Sch } \\
\text { itz }\end{array}$ & & & 1 & & $x=0)$ & &.$(\alpha=1)$ & rfl & $\begin{array}{l}\mathrm{p} \\
\mathrm{t} 3 \\
\end{array}$ & t4 \\
\hline 0,5 & 238 & & 0,84 & $-0,23$ & 080 & 986 & & & 994 & 0,0 & 0,0 \\
\hline 1,0 & 400 & & & & & & & & & & \\
\hline 1,5 & & & & & & & & & & & \\
\hline , & & & & & & & & & & & \\
\hline & & & & & & & & & & & \\
\hline , & & & & & & & & & & & \\
\hline 3,5 & & & & 5 & & & & & & 4 & 4 \\
\hline 4,0 & 41 & 540 & 70 & 847 & & 36 & & & & & \\
\hline 4,5 & & 501 & $\overline{796}$ & 864 & 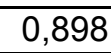 & 871 & & & 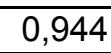 & & \\
\hline 5,0 & 47 & 0,632 & 0,8 & 0,87 & $0, \subseteq$ & b7 & & 57 & , & 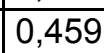 & \\
\hline 5,5 & & & & & & & & & & 4 & \\
\hline 0 & & & & & & & & & & & \\
\hline 5 & & & & 6 & & & & 44 & &, 475 & 4 \\
\hline 7,0 & & & 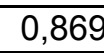 & & & 00 & & & & 47 &, 4 \\
\hline 7,5 & 562 & 755 &, 877 & & & 786 & 17 & 935 & 06 & 482 & - \\
\hline 8,0 & 565 & $\overline{7770}$ & $\overline{0,8}$ & & & 771 & & & 00 & 00 & 0,4 \\
\hline 8,5 & 568 & 784 & 0,8 & 0,928 & 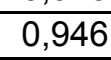 & , & 06 & & & & \\
\hline$\overline{9,0}$ & & & & & & & & & 00 & ד & \\
\hline & & & & & & & & & & 491 & \\
\hline & & & & & & & & & & & \\
\hline & & & & & & & & & 69 & & \\
\hline 1,0 & & & & & & & 79 & & 86 & & \\
\hline 1,5 & 574 & 0,84 & & & & & & & & 48 &, 4 \\
\hline
\end{tabular}




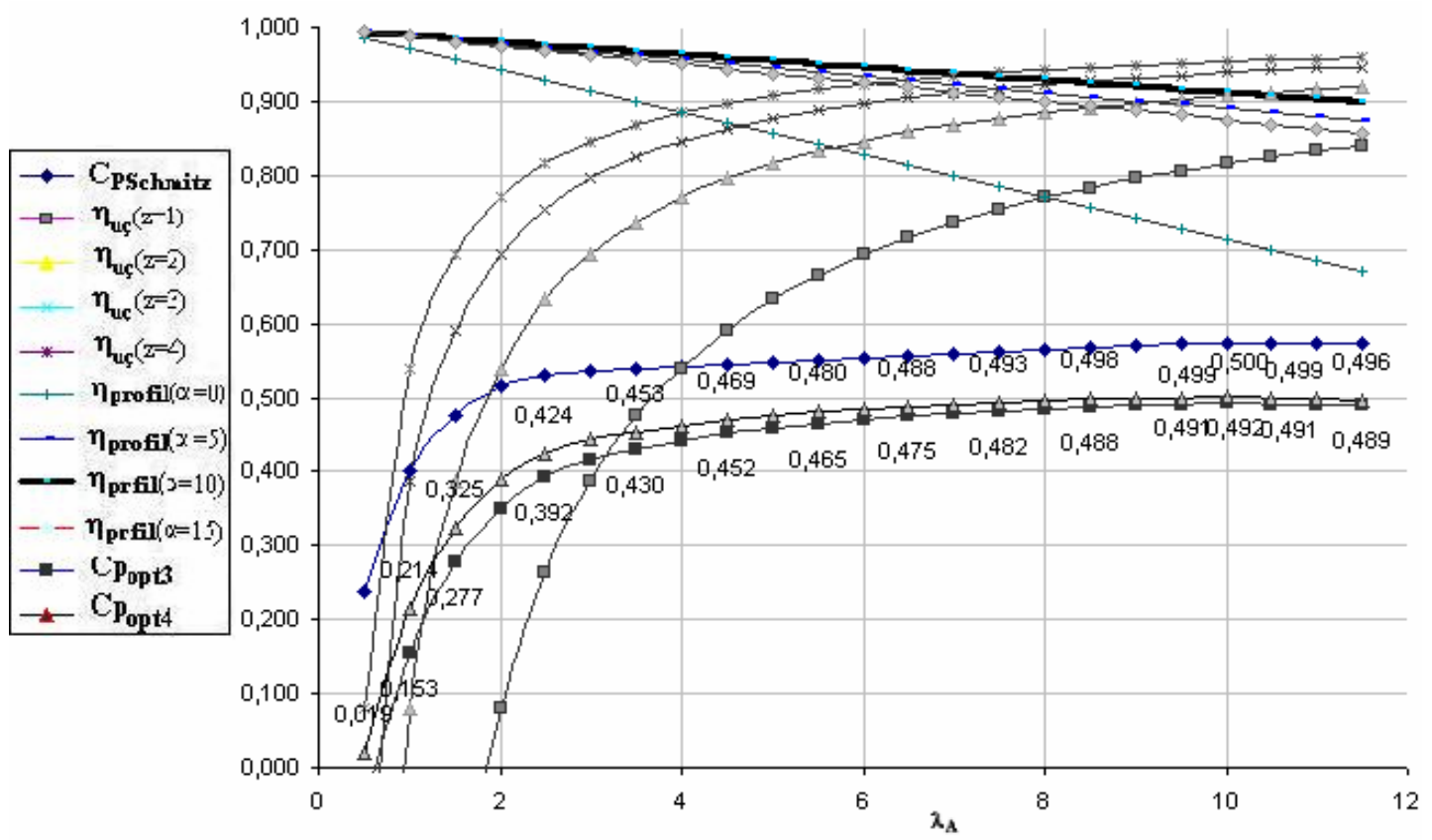

Figure 3. Plot of the values of the profile type LS-1

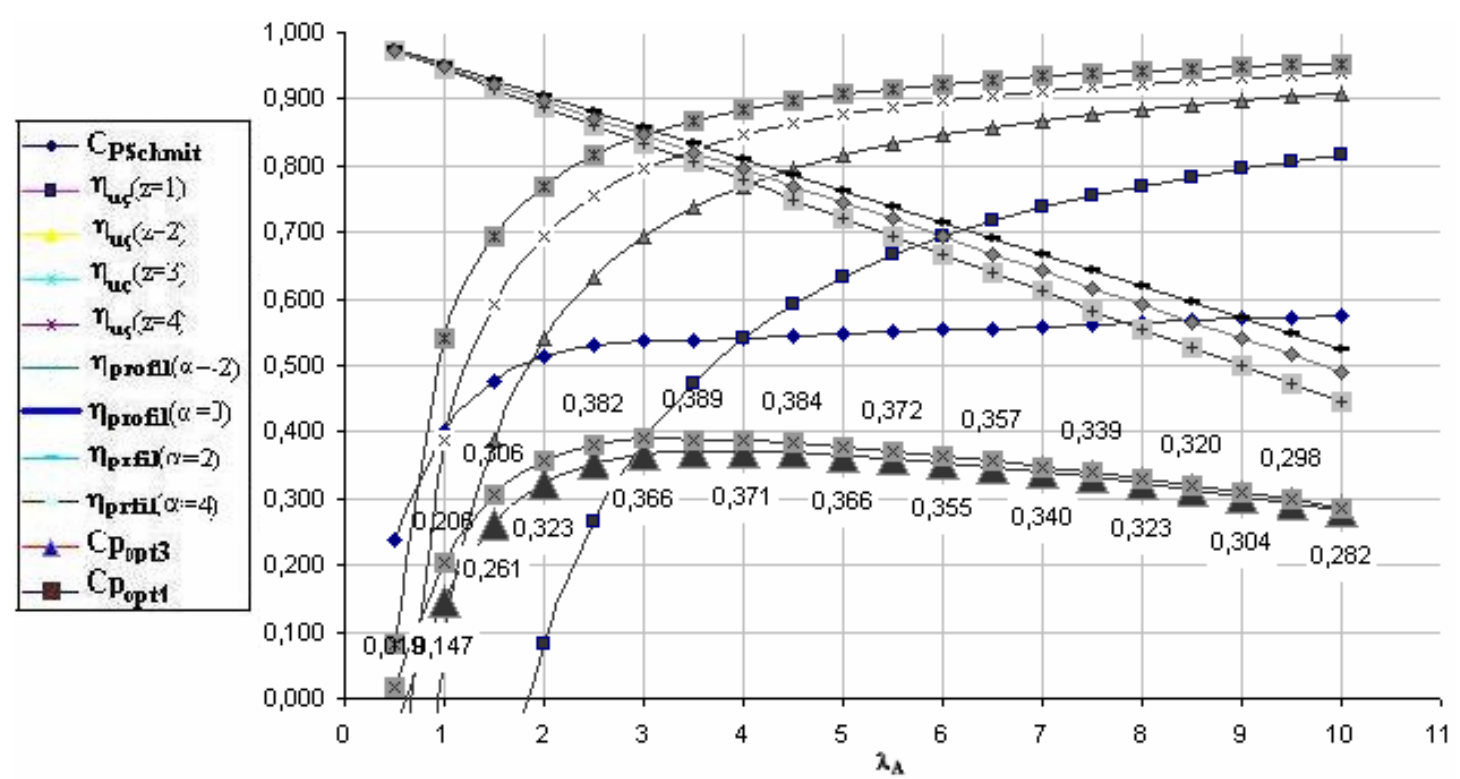

Figure 4. Plot of the values of the profile type Clark Y 
Table 4. Calculated values for the profile type Clark Y

\begin{tabular}{|r|c|c|c|c|c|c|c|c|c|r|r|}
\hline$\lambda \mathrm{A}$ & $\begin{array}{c}\mathrm{C}_{\text {PSch }} \\
\text { mitz }\end{array}$ & $\begin{array}{c}\eta_{\text {end }} \\
(\mathrm{z}=1)\end{array}$ & $\begin{array}{c}\eta_{\text {end }} \\
(\mathrm{z}=2)\end{array}$ & $\begin{array}{c}\eta_{\text {end }}(\mathrm{z}=3) \\
(\mathrm{z}=4)\end{array}$ & $\begin{array}{c}\eta_{\text {profile }} \\
(\alpha=-2)\end{array}$ & $\begin{array}{c}\eta_{\text {profile }} \\
.(\alpha=0)\end{array}$ & $\begin{array}{c}\eta_{\text {profile }} \\
(\alpha=2)\end{array}$ & $\begin{array}{c}\eta_{\text {profile }} \\
(\alpha=4)\end{array}$ & $\mathrm{C}_{\text {popt3 }}$ & $\mathrm{C}_{\text {popt4 }}$ \\
\hline 0,5 & 0,238 & $-2,680$ & $-0,840$ & $-0,23$ & 0,080 & 0,972 & 0,976 & 0,976 & 0,974 & $-0,05$ & 0,02 \\
\hline 1,0 & 0,400 & $-0,840$ & 0,080 & 0,387 & 0,540 & 0,944 & 0,952 & 0,952 & 0,949 & 0,15 & 0,21 \\
\hline 1,5 & 0,475 & $-0,227$ & 0,387 & 0,591 & 0,693 & 0,917 & 0,929 & 0,929 & 0,923 & 0,26 & 0,31 \\
\hline 2,0 & 0,515 & 0,080 & 0,540 & 0,693 & 0,770 & 0,889 & 0,905 & 0,905 & 0,898 & 0,32 & 0,36 \\
\hline 2,5 & 0,531 & 0,264 & 0,632 & 0,755 & 0,816 & 0,861 & 0,881 & 0,881 & 0,872 & 0,35 & 0,38 \\
\hline 3,0 & 0,537 & 0,387 & 0,693 & 0,796 & 0,847 & 0,833 & 0,857 & 0,857 & 0,847 & 0,37 & 0,39 \\
\hline 3,5 & 0,538 & 0,474 & 0,737 & 0,825 & 0,869 & 0,806 & 0,833 & 0,833 & 0,821 & 0,37 & 0,39 \\
\hline 4,0 & 0,541 & 0,540 & 0,770 & 0,847 & 0,885 & 0,778 & 0,810 & 0,810 & 0,796 & 0,37 & 0,39 \\
\hline 4,5 & 0,544 & 0,591 & 0,796 & 0,864 & 0,898 & 0,750 & 0,786 & 0,786 & 0,770 & 0,37 & 0,38 \\
\hline 5,0 & 0,547 & 0,632 & 0,816 & 0,877 & 0,908 & 0,722 & 0,762 & 0,762 & 0,745 & 0,37 & 0,38 \\
\hline 5,5 & 0,550 & 0,665 & 0,833 & 0,888 & 0,916 & 0,694 & 0,738 & 0,738 & 0,719 & 0,36 & 0,37 \\
\hline 6,0 & 0,553 & 0,693 & 0,847 & 0,898 & 0,923 & 0,667 & 0,714 & 0,714 & 0,694 & 0,36 & 0,37 \\
\hline 6,5 & 0,556 & 0,717 & 0,858 & 0,906 & 0,929 & 0,639 & 0,690 & 0,690 & 0,668 & 0,35 & 0,36 \\
\hline 7,0 & 0,559 & 0,737 & 0,869 & 0,912 & 0,934 & 0,611 & 0,667 & 0,667 & 0,643 & 0,34 & 0,35 \\
\hline 7,5 & 0,562 & 0,755 & 0,877 & 0,918 & 0,939 & 0,583 & 0,643 & 0,643 & 0,617 & 0,33 & 0,34 \\
\hline 8,0 & 0,565 & 0,770 & 0,885 & 0,923 & 0,943 & 0,556 & 0,619 & 0,619 & 0,592 & 0,32 & 0,33 \\
\hline 8,5 & 0,568 & 0,784 & 0,892 & 0,928 & 0,946 & 0,528 & 0,595 & 0,595 & 0,566 & 0,31 & 0,32 \\
\hline 9,0 & 0,570 & 0,796 & 0,898 & 0,932 & 0,949 & 0,500 & 0,571 & 0,571 & 0,541 & 0,30 & 0,31 \\
\hline 9,5 & 0,572 & 0,806 & 0,903 & 0,935 & 0,952 & 0,472 & 0,548 & 0,548 & 0,515 & 0,29 & 0,30 \\
\hline 10 & 0,574 & 0,816 & 0,908 & 0,939 & 0,954 & 0,444 & 0,524 & 0,524 & 0,490 & 0,28 & 0,29 \\
\hline
\end{tabular}

Based on the graphs given in Figures 2,3,4 it can be seen that the optimum power factor is obtained from the 4-blade turbines. However considering the financial cost analysis between 3 and 4-blade turbines, it is concluded that the optimum blade number is 3 for electric power production.

\section{REFERENCES}

1. E. Hau, Windkraftanlangen, Springer Verlag, pp. 110-113, Berlin, Germany, 1996.

2. R. Gasch, Windkraftanlangen, B. G. Teubner Verlag, 157-158, Stuttgart, Germany, 1996.

3. B. Jones, Elements of Aerodynamics, John Wiley\& Sons, 73-158, New York, USA, 1950.

4. A. Özdamar, Introduction to Wind Energy and Wind Turbines, Proceedings of renewable energy symposium, 242-254, Izmir, Turkey, 2001.

5. N. S. Çetin, A. Özdamar, Ö. Kara, and G. Örer, Research in to optimal rate of rotation in wind, Proceedings of $6^{\text {th }}$ Turkish-German Energy Symposium, İzmir, Turkey, 2001.

6. A. Özdamar, M. G. Kavas, Research into design of wind turbine blade, Proceedings of sun day and exhibit, 151 . 